Albert Parker*

\title{
Minimum 60 years of recording are needed to compute the sea level rate of rise in the Western South Pacific
}

\begin{abstract}
Sea levels generally oscillate with multi-decadal periodicities worldwide with up to the quasi-60 years detected in many tide gauges. Nevertheless, the most part of the literature on sea levels computes apparent rates of rise of sea levels much larger than the legitimate by using short time windows in selected locations only covering part of a valley-to-peak of this multi-decadal oscillation. It is shown in this paper that along the Pacific coast of Australia the sea levels oscillate with a frequency close to the Southern Ocean Index (SOI) oscillation of 19 years and a lower frequency of about 60 years. The rates of rise of sea levels computed by linear fitting of the data recorded since the early 1990s in selected locations of the Australian Pacific coastline and in the tropical Pacific islands are from a valley of the peak and valley oscillations and are much higher than the legitimate long term values.
\end{abstract}

Keywords: sea level acceleration, ocean thermal expansion, subsidy, Pacific atoll dynamic

\footnotetext{
*Corresponding Author: Albert Parker: School of Aerospace, Mechanical, and Manufacturing Engineering, RMIT University, Bundoora, VIC 3083 Australia, E-mail: albert.parker@rmit.edu.au
}

\section{Introduction}

The sea levels around the world are rising and it is claimed that the global rate of rise of sea levels has been considerably increased over the last 25 years [1-3]. The global mean sea level (GMSL) reconstruction 1870 to 2004 of [1] proposes a rate of rise of $1.4 \mathrm{~mm} /$ year. The reconstruction of GMSL 1950 to 2009 of [2] suggests a rate of rise of sea level of $1.7 \mathrm{~mm} /$ year. The recent reconstruction of the GMSL [3] gives a rate of rise of sea level of about $3.3 \mathrm{~mm} /$ year from 1993 to 2009. This claimed increase in the rate of rise of sea levels is attributed to the thermal expansion of the warming oceans and the contribution of land-based ice due to increased melting [3].

It has been shown in recent papers, that all the long term tide gauges of the world recording the monthly sea levels since the latest 1800s - beginning of the 1900s consistently show periodic oscillations about an almost per- fectly linear trend over the last century [4-11]. The longer of these oscillations have a quasi- 60 year periodicity, and it has been suggested that what has been claimed as present sea level acceleration and presently higher than before rates of rise of sea levels is only the result of the selective focusing on the latest valley to peak movement of a multi decadal oscillation [4-11].

While for other oceans it has been published already that the climate may oscillate with a quasi-60 years periodicity, as example the AMO for the North Atlantic coast of the United States, and the seas may also oscillate follow this periodicity, for the Western South Pacific, the only correlation proposed so far for the sea level is the SOI with a multi-decadal periodicity of about 19 years $[19,20]$.

It is shown here that also for the Western South Pacific seas there is a much longer periodicity, close to the periodicity of a long SOI [21], of quasi-60 years. The quasi-60 years oscillations common to the most part of the oceans are discussed in $[7,8,10,11$, and 22].

\section{The multi-decadal oscillations of the Western and Tropical South Pacific seas}

The existence of multi-decadal oscillations of periodicity exceeding the 19 years is clear when more than 100 years of monthly average sea levels are available. Unfortunately, the only two tide gauges of the area satisfying this conditions are those of Sydney, NSW and Auckland, NZ. Obviously, the length of the record determines the maximum detectable periodicity that is much smaller than this length. Therefore, other longer periodicities can not be excluded.

The method is described in details in the references, in particular [7] and [11]. From a distribution of measured points $\mathrm{x}_{i}, \mathrm{y}_{i} \mathrm{i}=1, \mathrm{n}$ where $\mathrm{x}$ is the time and $\mathrm{y}$ is the climate parameter of interest, the monthly average sea level or a climate index, the linear trend is first computed by linearly fitting the distribution. Then, the oscillations of the distri- 
bution around the linear trend are studied by Fourier analysis.

Figure 1 presents the departure from the linear trend of the monthly average sea levels for Sydney, NSW and Auckland, NZ (from [12])., plus a long BEST (from [18]) or a long SOI (from [21]). The monthly oscillations are analysed with a statistical tool to obtain the periodogram.

The time series analysis produces results for Sydney, NSW and Auckland, NZ not too far from the analysis of a BEST (Bivariate ENSO Time series) calculated from combining a standardized Southern Ocean Index (SOI) and a standardized Nino3.4 SST time series (from [18]).The signatute is also not too far from a long SOI (from [21]). Clearly, all these time series have a longer periodicity in the area of 600 to 800 months, or 50 to 65 years.

The time series analysis is clearly very sensitive about this periodicity because there are not too many data points to detect this longer periodicity and the signal is quite noisy.

The monthly average sea levels oscillate much closely to the SOI index (locations of peaks and valleys) than the BEST index. Small differences also emerge from the comparison of the sea levels time series with the SOI time series, but the level of correlation of monthly average sea levels and climate indices is definitively good.

\section{Sea level rates of rise inferred from short records started in a valley of the peaks and valleys oscillations}

The multi-decadal swings oscillate about a smooth longer term trend. A simple analysis based on linear fittings of the monthly average sea levels (MSL) measured in different geographical locations over different time windows is proposed to expose the cherry-picking of the short time window proper of many recent analyses of sea levels.

It has been claimed that the sea levels are sharply accelerating in the Pacific and Australia by focusing on periods covering less than the last 20 years of data in few selected locations [13-16]. The South Pacific Sea Level and Climate Monitoring Project [13-14] and the Australian Baseline Sea Level Monitoring Project [15-16] both started early 1990s, roughly same time of the satellite reconstruction of the global mean sea level GMSL [17].

The Australian Baseline Sea Level Monitoring Project first sea level trends were produced in January 1999, with on average less than 10 years of recorded data in 14 loca-
Table 1. Recent short-term sea level trends in The Australian Baseline Sea Level Monitoring project area based upon SEAFRAME data through June, 2012 (from [16]).

\begin{tabular}{|c|c|c|c|}
\hline Location & Lat / Long & Installation & $\begin{array}{l}\text { Trend } \\
\mathrm{mm} / \mathrm{yr}\end{array}$ \\
\hline Cocos Islands & $\begin{array}{l}12^{\circ} 07^{\prime} 07.1^{\prime \prime} \mathrm{S} / \\
96^{\circ} 53^{\prime} 30.9^{\prime \prime} \mathrm{E}\end{array}$ & Sep-92 & 8.3 \\
\hline Groote Eylandt & $\begin{array}{l}13^{\circ} 51^{\prime} 36.2^{\prime \prime} \mathrm{S} / \\
136^{\circ} 24^{\prime} 56.1^{\prime \prime} \mathrm{E}\end{array}$ & Sep-93 & 9.2 \\
\hline Darwin & $\begin{array}{l}12^{\circ} 28^{\prime} 18.4^{\prime \prime} \mathrm{S} / \\
130^{\circ} 50^{\prime} 45.1^{\prime \prime} \mathrm{E}\end{array}$ & May-90 & 8.8 \\
\hline Broome & $\begin{array}{l}18^{\circ} 00^{\prime} 03.0^{\prime \prime} \mathrm{S} / \\
122^{\circ} 13^{\prime} 07.1^{\prime \prime} \mathrm{E}\end{array}$ & Nov-91 & 9.3 \\
\hline Hillarys & $\begin{array}{l}31^{\circ} 49^{\prime} 32.0^{\prime \prime} \mathrm{S} / \\
115^{\circ} 44^{\prime} 18.9^{\prime \prime} \mathrm{E}\end{array}$ & Nov-91 & 10.2 \\
\hline Esperance & $\begin{array}{l}33^{\circ} 52^{\prime} 15.2^{\prime \prime} \mathrm{S} / \\
121^{\circ} 53^{\prime} 43.3^{\prime \prime} \mathrm{E}\end{array}$ & Mar-92 & 6.6 \\
\hline Thevenard & $\begin{array}{l}32^{\circ} 08^{\prime} 56.2^{\prime \prime} \mathrm{S} / \\
133^{\circ} 38^{\prime} 28.8^{\prime \prime} \mathrm{E}\end{array}$ & Mar-92 & 5 \\
\hline Port Stanvac & $\begin{array}{l}35^{\circ} 06^{\prime} 31.0^{\prime \prime} \mathrm{S} / \\
138^{\circ} 28^{\prime} 1.3^{\prime \prime} \mathrm{E}\end{array}$ & Jun-92 & 4.7 \\
\hline Portland & $\begin{array}{l}38^{\circ} 20^{\prime} 36.4^{\prime \prime} \mathrm{S} / \\
141^{\circ} 36^{\prime} 47.4^{\prime \prime} \mathrm{E}\end{array}$ & Jul-91 & 3.5 \\
\hline Lorne & $\begin{array}{l}38^{\circ} 32^{\prime} 49.4^{\prime \prime} \mathrm{S} / \\
143^{\circ} 59^{\prime} 19.8^{\prime \prime} \mathrm{E}\end{array}$ & Jan-93 & 3 \\
\hline Stony Point & $\begin{array}{l}38^{\circ} 22^{\prime} 19.7^{\prime \prime} \mathrm{S} / \\
145^{\circ} 13^{\prime} 28.9^{\prime \prime} \mathrm{E}\end{array}$ & Jan-93 & 2.9 \\
\hline Burnie & $\begin{array}{l}41^{\circ} 03^{\prime} 0.3^{\prime \prime} \mathrm{S} / \\
145^{\circ} 54^{\prime} 54.0^{\prime \prime} \mathrm{E}\end{array}$ & Sep-92 & 3.3 \\
\hline Spring Bay & $\begin{array}{l}42^{\circ} 32^{\prime} 45.1^{\prime \prime} \mathrm{S} / \\
147^{\circ} 55^{\prime} 57.8^{\prime \prime} \mathrm{E}\end{array}$ & May-91 & 3.5 \\
\hline Port Kembla & $\begin{array}{l}34^{\circ} 28^{\prime} 25.5^{\prime \prime} \mathrm{S} / \\
150^{\circ} 54^{\prime} 42.7^{\prime \prime} \mathrm{E}\end{array}$ & Jul-91 & 3.1 \\
\hline Rosslyn Bay & $\begin{array}{l}23^{\circ} 09^{\prime} 39.7^{\prime \prime} \mathrm{S} / \\
150^{\circ} 47^{\prime} 24.6^{\prime \prime} \mathrm{E}\end{array}$ & Jun-92 & 3.9 \\
\hline Cape Ferguson & $\begin{array}{l}19^{\circ} 16^{\prime} 38.4^{\prime \prime} \mathrm{S} / \\
147^{\circ} 03^{\prime} 30.4^{\prime \prime} \mathrm{E}\end{array}$ & Sep-91 & 4.7 \\
\hline
\end{tabular}

tions. The latest trends have been proposed in the June 2012 report [16] with still less than 20 years of recorded data in 13 locations (1 location has been decommissioned).

The measurements are collected with the SEAFRAME equipment [13-16] and the sea level results are corrected for barometric pressure and land motion through satellite GPS.

The South Pacific Sea Level and Climate Monitoring Project first sea level trends were produced in January 2006, with on average less than 10 years of recorded data in 12 locations. The latest trends have been proposed in the June 2012 report [14] with still less than 20 years of recorded data.

These measurements are also collected with the SEAFRAME. The sea level results are similarly corrected for barometric pressure and land motion. 

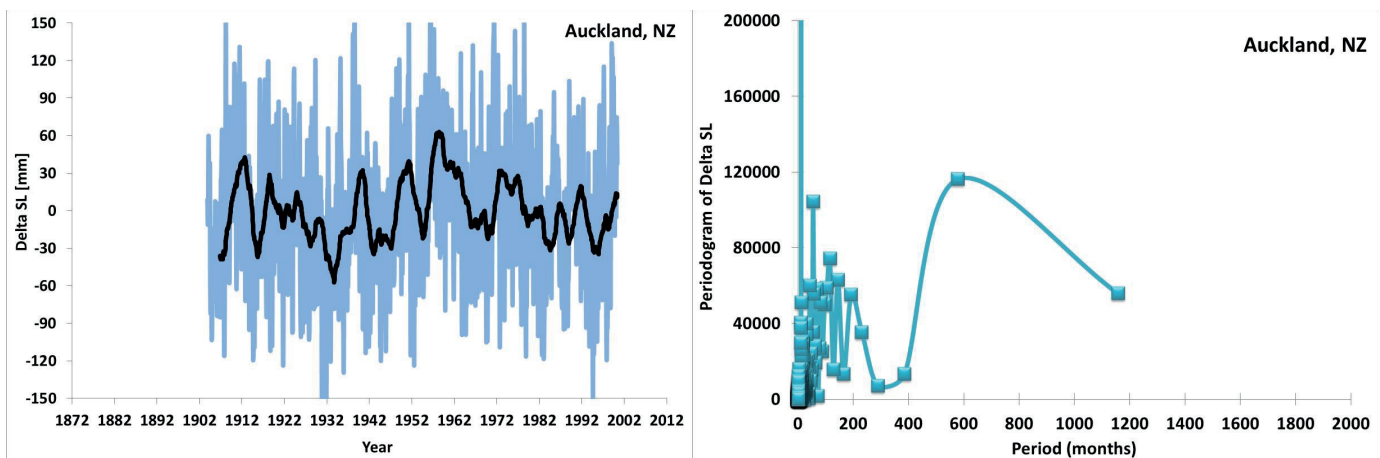

(a)

(b)
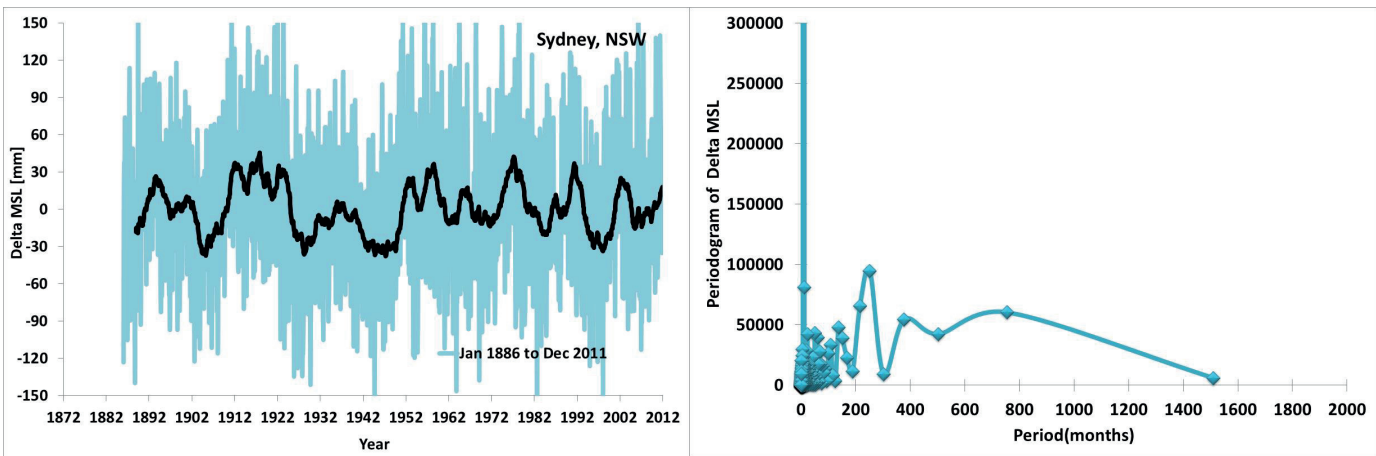

(c)

(d)
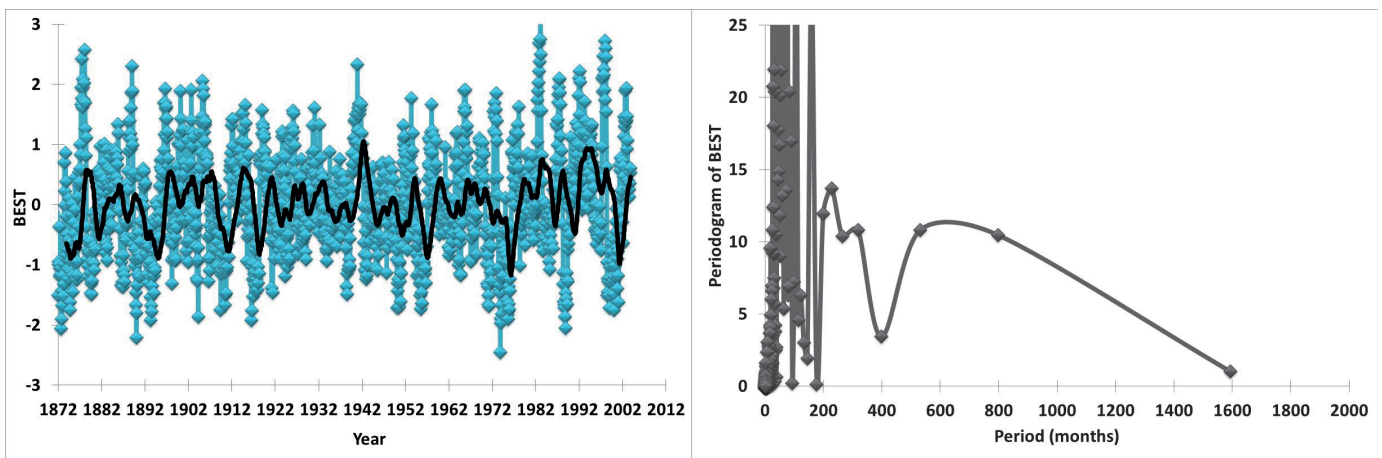

(e)

(f)
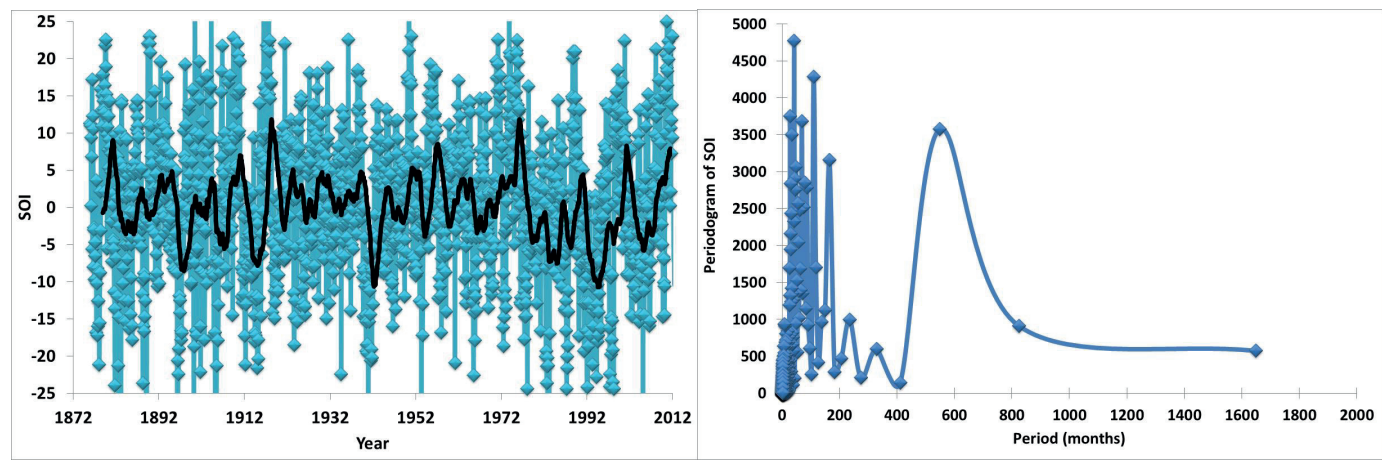

(g)

(h)

Fig. 1. Monthly average sea level oscillations about the linear trend in the Sydney, NSW and Auckland, NZ tide gauges and periodograms from their time series analysis. Monthly values of BEST and SOI indices and their periodograms. 36 months moving averages superimposed. 
Table 2. Recent short-term sea level trends in The South Pacific Sea Level \& Climate Monitoring Project area based upon SEAFRAME data through June, 2012 (from [14]).

\begin{tabular}{|c|c|c|c|}
\hline Location & Lat / Long & Installation & $\begin{array}{l}\text { Trend } \\
\mathrm{mm} / \mathrm{yr}\end{array}$ \\
\hline Cook Is & $\begin{array}{l}21^{\circ} 12^{\prime} 17.1^{\prime \prime} \mathrm{S} / \\
159^{\circ} 47^{\prime} 5.2^{\prime \prime} \mathrm{W}\end{array}$ & Feb-93 & 5.7 \\
\hline Tonga & $\begin{array}{l}21^{\circ} 8^{\prime} 12.5^{\prime \prime} \mathrm{S} / \\
175^{\circ} 10^{\prime} 50.5^{\prime \prime} \mathrm{W}\end{array}$ & Jan-93 & 8.9 \\
\hline Fiji & $\begin{array}{l}17^{\circ} 36^{\prime} 17.7^{\prime \prime} \mathrm{S} / \\
177^{\circ} 26^{\prime} 17.7^{\prime \prime} \mathrm{E}\end{array}$ & Oct-92 & 5.6 \\
\hline Vanuatu & $\begin{array}{l}17^{\circ} 45^{\prime} 19.2^{\prime \prime} \mathrm{S} / \\
168^{\circ} 18^{\prime} 27.7^{\prime \prime} \mathrm{E}\end{array}$ & Jan-93 & 5 \\
\hline Samoa & $\begin{array}{l}13^{\circ} 49^{\prime} 36.4^{\prime \prime} \mathrm{S} / \\
171^{\circ} 45^{\prime} 40.7^{\prime \prime} \mathrm{W}\end{array}$ & Feb-93 & 7.5 \\
\hline Tuvalu & $\begin{array}{l}8^{\circ} 30^{\prime} 8.9^{\prime \prime} \mathrm{S} / \\
179^{\circ} 11^{\prime} 42.6^{\prime \prime} \mathrm{E}\end{array}$ & Mar-93 & 4 \\
\hline Kiribati & $\begin{array}{l}1^{\circ} 21^{\prime} 54.2^{\prime \prime} \mathrm{N} / \\
172^{\circ} 55^{\prime} 58.8^{\prime \prime} \mathrm{E}\end{array}$ & Dec-92 & 3.1 \\
\hline Nauru & $\begin{array}{l}0^{\circ} 31^{\prime} 45.9^{\prime \prime} \mathrm{S} / \\
166^{\circ} 54^{\prime} 36.2^{\prime \prime} \mathrm{E}\end{array}$ & Jul-93 & 4 \\
\hline Solomon Is. & $\begin{array}{l}9^{\circ} 25^{\prime} 44.1^{\prime \prime} \mathrm{S} / \\
159^{\circ} 57^{\prime} 19.3^{\prime \prime} \mathrm{E}\end{array}$ & Jul-94 & 8.3 \\
\hline PNG & $\begin{array}{l}2^{\circ} 2^{\prime} 31.5^{\prime \prime} \mathrm{S} / \\
147^{\circ} 22^{\prime} 25.6^{\prime \prime} \mathrm{E}\end{array}$ & Sep-94 & 8.3 \\
\hline FSM & $\begin{array}{l}6^{\circ} 58^{\prime} 49.9^{\prime \prime} \mathrm{N} / \\
158^{\circ} 12^{\prime} 0.8^{\prime \prime} \mathrm{E}\end{array}$ & Dec-01 & 17.8 \\
\hline Marshall Is. & $\begin{array}{l}7^{\circ} 6^{\prime} 21.7^{\prime \prime} \mathrm{N} / \\
171^{\circ} 22^{\prime} 22.1^{\prime \prime} \mathrm{E}\end{array}$ & May-93 & 5.7 \\
\hline
\end{tabular}

The very large rates of rise of sea levels of Table 1 ( $5.6 \mathrm{~mm} /$ year) and Table 2 (7.0 mm/year) have been used to claim a huge acceleration of sea levels from the prior rates of rise, these latter obviously computed with other methods in other locations. These very large rates of rise of sea levels are mostly the result of misinterpreted multidecadal natural oscillations rather than the effect of the anthropogenic carbon dioxide emission.

\section{Sea level rates of rise inferred from longer records}

The selective picking of short records is evident as soon as longer records are available. Figure 2 presents an analysis of the tide gauge results for Sydney, NSW (from [12]).

Figure 2.a presents the result of the linear fitting of the last 19 years of data collected in Sydney, NSW. From this picture one could claim that the sea level has been rising in Sydney at a rate of $3.16 \mathrm{~mm}$ /year since January 1993. But as soon as more data became available and is properly analysed, it is obvious the claim is wrong.

Figure 2.b presents all the data available for Sydney, from January 1886 to December 2011, collected in two different tide gauges which have many decades of successful overlapping to produce a high quality record. The average sea level rate of rise is a $0.92 \mathrm{~mm} /$ year, less than one third of the short term value of Figure 2.a.

From Figure 1, there is a clear quasi-60 years multidecadal oscillations, and this translates in the minimum requirement of 60-70 years of continuously recorded data to infer any reasonably accurate value for the rate of rise of sea levels.

If we compute the present sea level rate of rise by linear fitting of 60 years of data at any time, this parameter is presently reducing and less than $25 \%$ of the short term result.

The influence of the oscillating behaviour on the apparent rate of rise of sea levels is evident in Figure 2.c. The sea level rate of rise is computed by linear fitting of different record lengths changing the starting date up to the present time. With lengths smaller than one 60 years periodicity the computed values are very far from the legitimate longer term trend values. If we assume that the almost 130 years full record length is the true long term trend SLR, the difference in between the SLR value computed with less data and this value is the SLR error of Figure 2.d.

As previously reported in [11], the Sydney record is acceleration-free, as proved by the regular oscillations about the zero value of the time derivative of the rate of rise of sea levels compututed by using at all the times all the data collected so far.

\section{Which are then the correct rates of rise of sea levels for the stations of Tables 1 and 2?}

This answer is not simple, being the behaviour of sea levels recorded by one tide gauge not necessarily transferable to other neighboring tide gauges. A simplistic solution should be to consider only $30 \%$ of the values in the table the legitimate long term rate of rise. However, additional measurements collected in same locations or neighboring locations may help to better understand the real rate of rise of sea levels. The error vs. record length of Figure 2.d may only be used as a very rough indication of the error the values computed with larger but still insufficient time windows may have. 


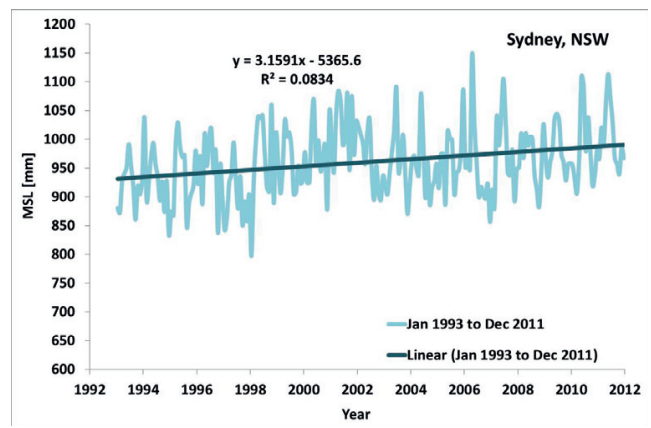

(a)

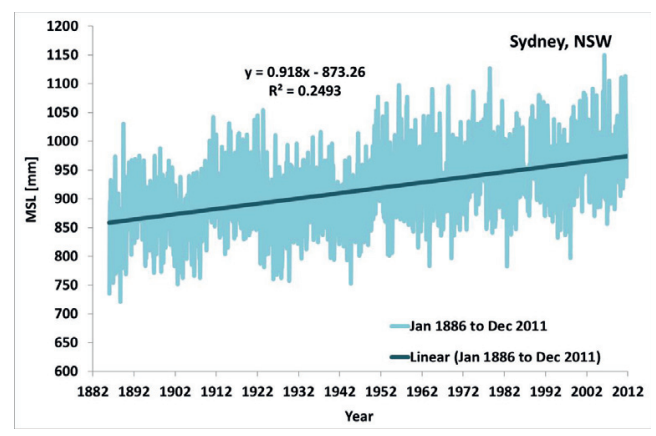

(b)

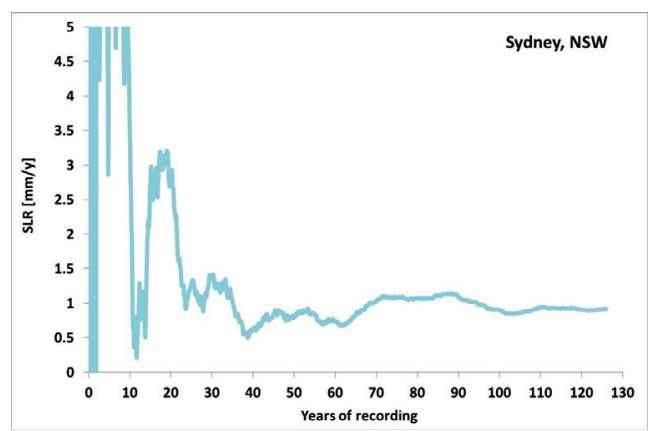

(c)

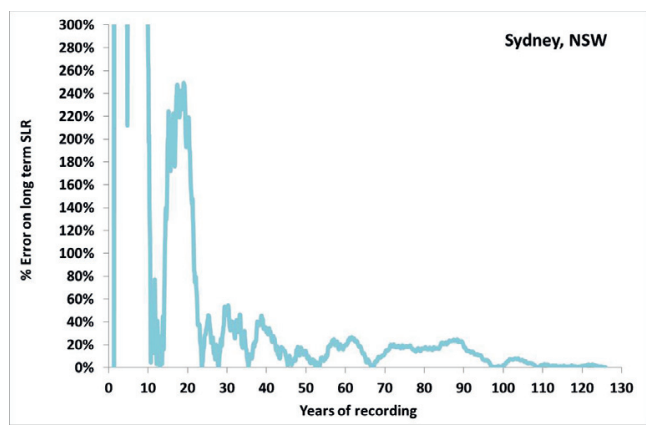

(d)

Fig. 2. Rate of rise of sea level in Sydney, NSW: a) apparent rate of rise of sea level obtained by focusing on the last 19 years of data starting from a valley of the peak and valley multi-decadal oscillation; b) correct value obtained by using all the data covering almost 130 years; c) present rate of rise of sea levels as a function of the time window considered; d) error on the estimation of the long term trend based on the length of the record. Further details in [12].
The distributions of relative sea level trend estimates for tide gauges around Australia that have at least 25 years of hourly data on the NTC archive from the Australian Mean Sea Level Survey 2003 [19] and the Australian Mean Sea Level Survey 2009 [20] show minimal differences, with small changes in positive or negative from one survey to the other in the rate of sea level rise.

As written in [19], "The trend estimate will change as new data is accumulated, and its confidence interval or precision will improve with the length of the record. The minimum length of sea level record used in this survey is 25 years, which provides a reasonable initial estimate of the underlying long-term secular sea level trend aside from the effects of inter-annual and inter-decadal sea level fluctuations associated with variations in climate, such as El Nińo - Southern Oscillation and Pacific Decadal Oscillation. It also allows for a complete cycle of the nodal recession of the Moon, which has a period of 18.6 years."

"A striking feature is the degree of correlation in the annual sea levels, particularly anticlockwise from Darwin through to Victor Harbor. The annual sea levels are also strongly correlated with El Nińo - Southern Oscillation".

"Coherent inter-decadal sea level oscillations with periods of around 20 years are also notable, which can mask the longer-term secular trend and has implications for the length of record required to detect it."

These statements were fully correct, with the only information missed in the report [19] the existence of the quasi-60 years oscillation making the minimum record length longer.

\section{Individual station analysis}

Figure 3 presents the tide gauge results (from NOAA [12] and PSMSL [23]) plus the GPS height of nearby locations to detect subsidy (from SONEL [25]).

SONEL serves as the GNSS data assembly centre for the Global Sea Level Observing System (GLOSS), which is developed under the auspices of the IOC/Unesco. It works closely with the PSMSL by developing an integrated global observing system, which is linking both the tide gauge and the GNSS databases for a comprehensive service to the scientific community.

Majuro, Marshall Islands, Figure 3.a has two records, B (Latitude: 7.1 Longitude: 171.366667) and C (Latitude: 7.106028, Longitude: 171.372806) [12, 23] that may be combined to make a longer record. The 54 years composite record gives a rate of rise of $3.31 \mathrm{~mm} /$ year vs. the $5.7 \mathrm{~mm} /$ year of Table 2 computed by only considering the 
Majuro C result. Majuro B and Majuro C have 8 years of overlapping with perfect agreement in between the two results. The nearby GNSS Stations from SONEL [25] shows some subsidy, Figure 3.b.

Kwajalein, Marshall Islands (Latitude: 8.731667 Longitude: 167.735 ) has a record 66 years long with a rate of rise of $1.43 \mathrm{~mm}$ /year [12, 23] as shown in Figure 3.c. Kwajalein is affected by an icreasing subsidy in the recent years, Figure 3.d.

Pohnpei, Federated States of Micronesia has two records B (Latitude: 6.983333 Longitude: 158.233333) and C (Latitude: 6.980528 Longitude: 158.200222) [12, 23] that give a rate of rise of $3.87 \mathrm{~mm}$ /year over 37 years to compare with the $17.8 \mathrm{~mm} /$ year of Table 2 obtained by considering only the second record. The two tide gauges have a small but consistent overlapping of 3 years. The Pohnpei tide gauge is shown in Figure 3.e. The nearby subsiding GPS is shown in Figure 3.f. Kapingamarangi, Federated States Of Micronesia [12, 23] (Latitude: 1.1 Longitude: 154.783333) also has a rate of rise of $2.53 \mathrm{~mm} /$ year over 30 years. No GPS data are available for Kapingamarangi.

Funafuti, Tuvalu has two records. Funafuti (Latitude: -8.533333 Longitude: 179.216667) \& Funafuti B (Latitude: -8.502472 Longitude: 179.195167$)$ [12, 23] produce a composite record suggesting a rate of rise of $3.74 \mathrm{~mm}$ /year over 34 years vs. the $4 \mathrm{~mm} /$ year of Table 2 obtained by considering only the second tide gauge. The two tide gauges have a good overlapping over 8 years. The Funafuti composite tide gauge record is shown in Figure 3.g. The nearby GPS station also has subsidy, as shown in Figure 3.h.

Rabaul, PNG (Latitude: -4.2 Longitude: 152.183333) $[12,23]$ had a 1966 to 1997 rate of rise of sea level of $-2.59 \mathrm{~mm} /$ year to compare with the $8.3 \mathrm{~mm} /$ year of a neigboring location in Table 2. No GPS data is available nearby.

Honiara, Solomon Islands has two records. Honiara -II (Latitude: -9.433333 Longitude: 159.95) and Honiara B (Latitude: -9.428917 Longitude: 159.955361) [12, 23] produce a composite record suggesting a rate of rise of $2.80 \mathrm{~mm} /$ year over 37 years vs. the $8.3 \mathrm{~mm} /$ year of Table 2 obtained by considering only the second record. The composite tide gauge of Honiara is shown in Figure 3.i. The nearby GPS does not present a detectable subsidy as shown in Figure 3.j.

Penrhyn, Cook Islands (Latitude: -9.016667 Longitude: -158.066667$)[12,23]$ has a rate of rise of $2.41 \mathrm{~mm} /$ year over 33 years. No nearby GPS data is available in Penrhyn.

Rarotonga, Cook Islands has two records. Rarotonga (Latitude: -21.2 Longitude: -159.766667) and Rarotonga B (Latitude: -21.20475 Longitude: -159.784778) [12, 23] have a rate of rise of $1.51 \mathrm{~mm} /$ year over 35 years, vs. the
$5.7 \mathrm{~mm} /$ year of Table 2 obtained by considering only this latter tide gauge. Rarotonga and Rarotonga B also have 8 years of overlapping providing almost same results. The composite tide gauge of Rarotonga is shown in Figure 3.k. The nearby GPS does not present a detectable subsidy as shown in Figure 3.1.

Kanton Island, Kiribati has two records. Kanton Island (Latitude: -2.8 Longitude: -171.716667$)$ and Kanton Island B (Latitude: -2.816667 Longitude: -171.716667$)$, Kiribati [12, 23] produce a composite record of rate of rise $0.58 \mathrm{~mm} /$ year over 58 years vs. the $3.1 \mathrm{~mm} /$ year of another neigboring location in Table 2. No nearby GPS data is available in Kanton Island.

While there is no other record in Western Samoa, in the Americal Samoa, the Pago Pago record is worth considering.

Pago Pago, American Samoa (Latitude: -14.28 Longitude: -170.69 ) has a $2.07 \mathrm{~mm} /$ year SLR over 64 years. The Pago pago tide gauge result is shown in Figure 3.m, while the nearby GPS is shown in Figure 3.n. A recent strong subsidy seems to couple very well with a recent sea level rise.

Fiji are the only case where the high rate of rise of Tables 1 and 2 is confirmed by a longer record. Suva-A, Fiji (Latitude: -18.135678 Longitude: 178.422839) has a SLR of $6.30 \mathrm{~mm} /$ year over 40 years. The Suva tide gauge result is shown in Figure 3.o. The nearby GPS has a subsidy, Figure 3.p.

Along the coast of Australia, there is no acceleration of sea levels as already discussed [7-11]. Short time windows are responsible of apparently high rates of rise.

Cape Ferguson, QLD (Latitude: -19.277333 Longitude: 147.058444$)$ in Table 1 has the very close Townsville I, QLD (Latitude: -19.25 Longitude: 146.833333) tide gauge showing a $1.48 \mathrm{~mm} /$ year rate of rise computed over 51 years $[12,23]$ vs. the $3.48 \mathrm{~mm} /$ year of Table 1 .

For Rosslyn Bay, QLD (Latitude: -23.161028 Longitude: 150.790167 ) the rate of rise of Table 1 is $3.9 \mathrm{~mm} /$ year.

Nearby Bundaberg, Burnett Heads, QLD (Latitude: -24.766667 Longitude: 152.383333) [12, 23] has a rate of rise of $0.58 \mathrm{~mm} /$ year over 46 years.

For Port Kembla, NSW also considering the prior measurements Port Kembla II in addition to the latest Port Kembla results [12, 23] for a total record length of 46 years, the rate of rise of sea levels is $1.18 \mathrm{~mm} /$ year vs. the $3.1 \mathrm{~mm} /$ year of Table 1 .

Port Kembla, NSW (Latitude: -34.47375 Longitude: 150.911861) is not far from Sydney, NSW (Latitude: -33.85 Longitude: 151.233333) of Figure 2 [12].

Newcastle III \& V, NSW (Latitude: -32.916667 Longitude: 151.8 , Latitude: -32.924 Longitude: 151.788583 [12, 


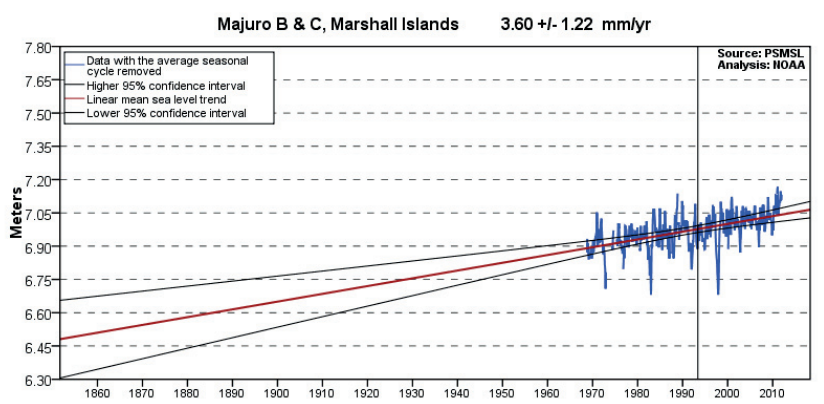

(a)

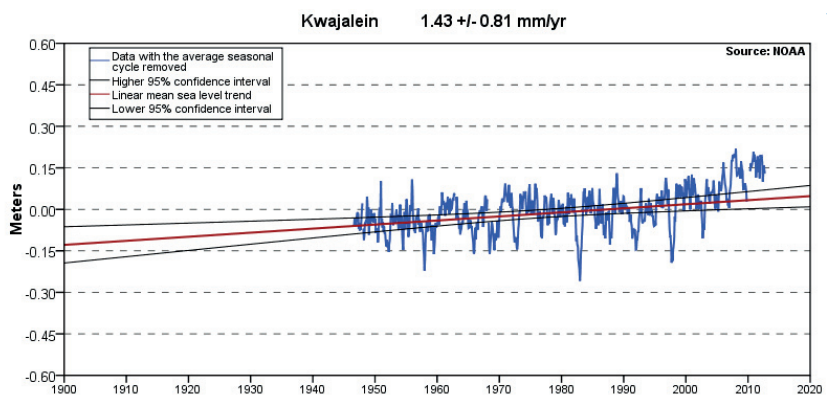

(c)

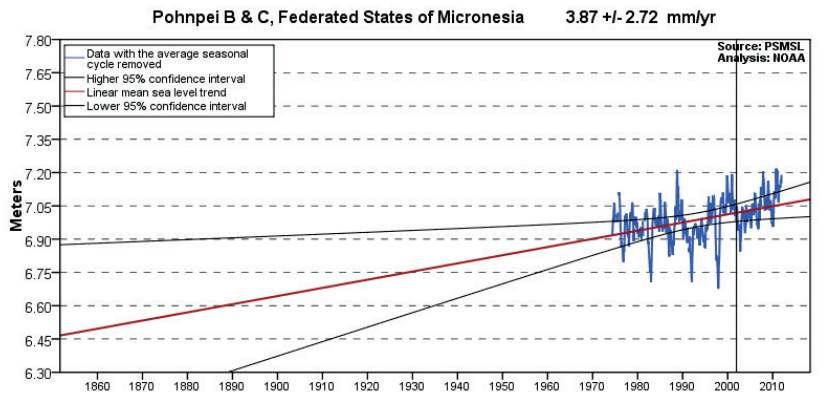

(e)

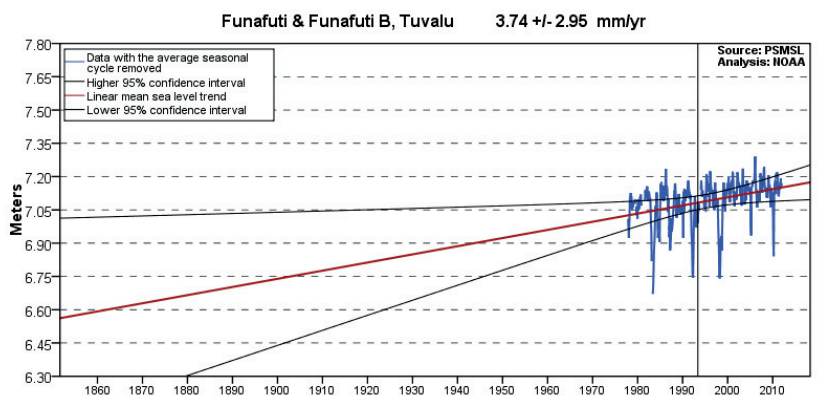

(g)

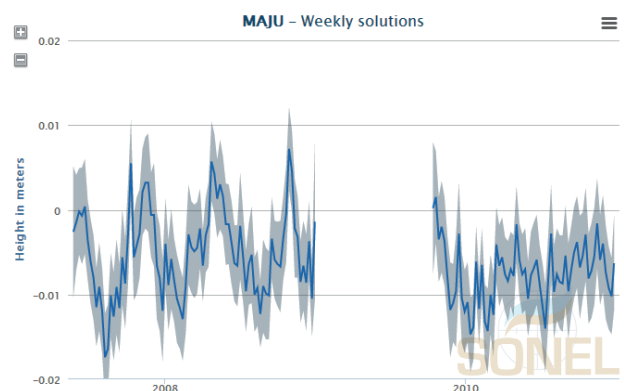

(b)

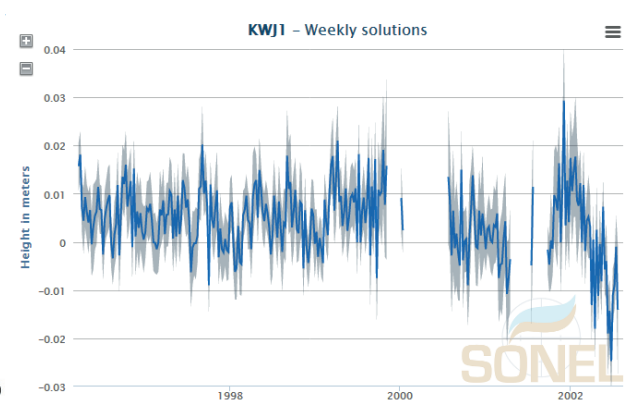

(d)

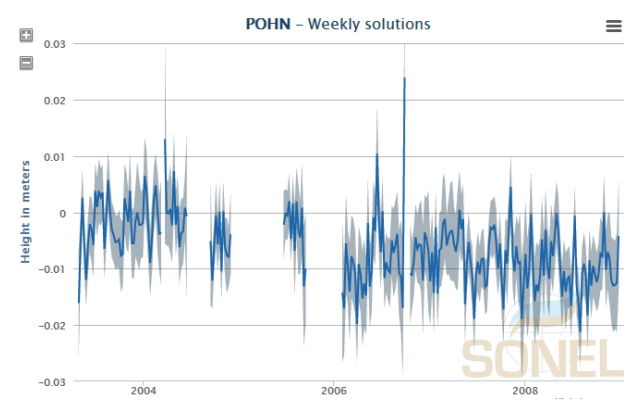

(f)

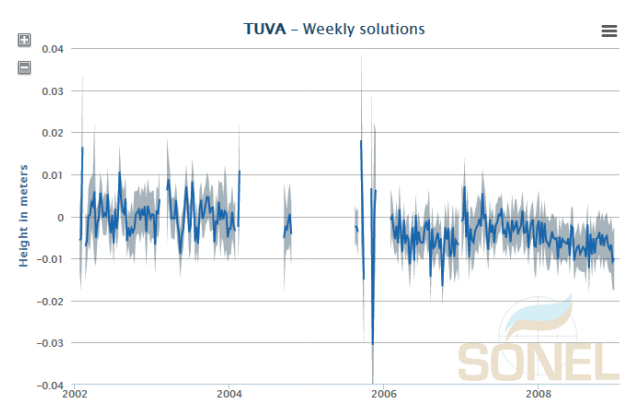

(h)

Fig. 3. Rate of rise of sea level (from [23]) and vertical height of closest GPS station (from [25]) in Western South Pacific island locations. The GPS data are scattered data only helpful to detect the presence or absence of a general subsidy for the area of the tide gauge. No conclusive statement can be made about the vertical stability of the tide gauge from these data. The reading of the tide gauge may also be biased upwards or downwards by other factors additional to subsidence or uplift. 

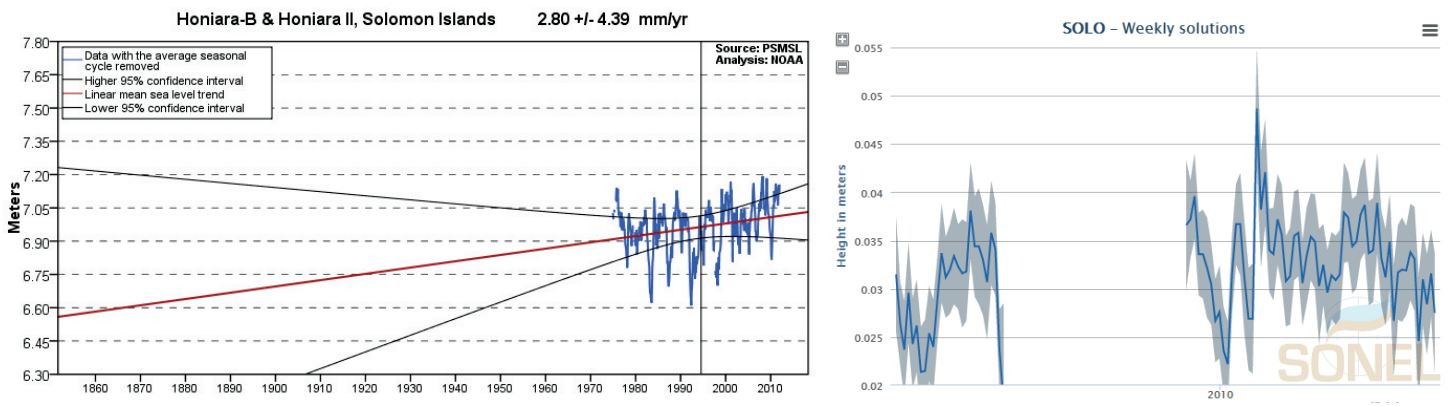

(i)

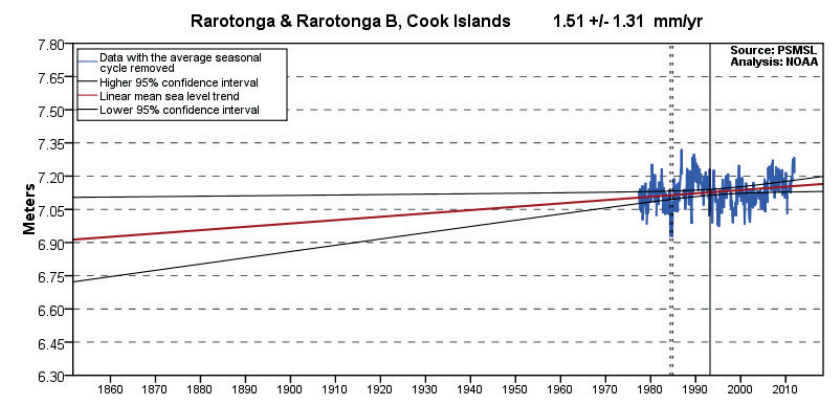

(k)

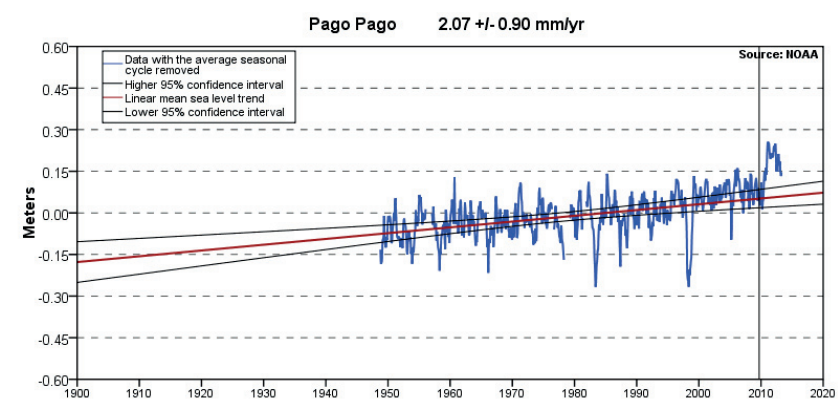

(m)

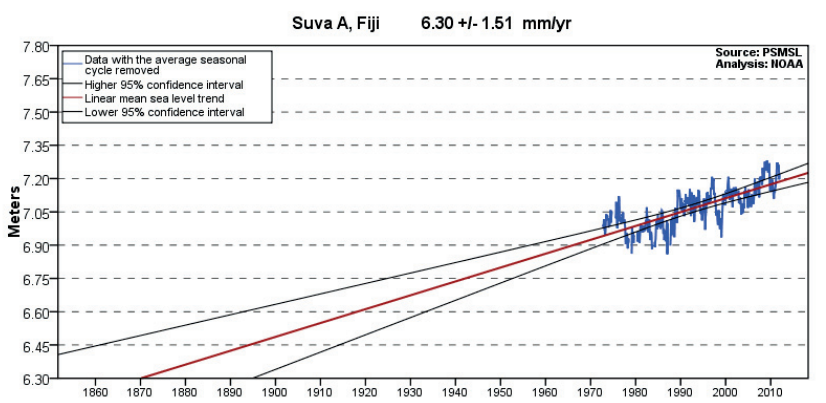

(o) (j)

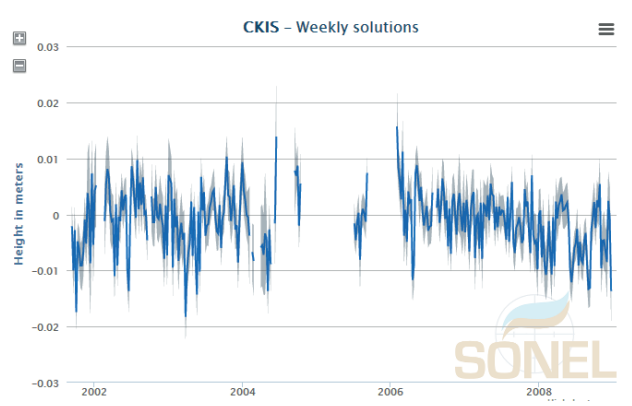

(l)

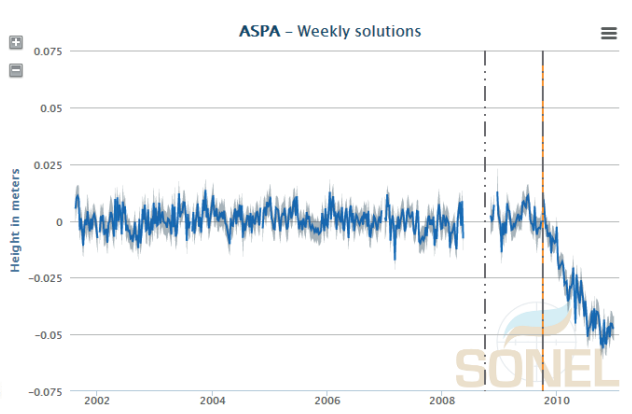

(n)

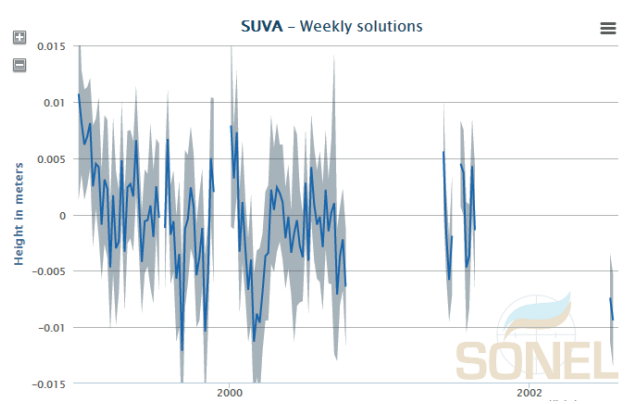

(p)

Fig. 3. - continue - Rate of rise of sea level (from [23]) and vertical height of closest GPS station (from [25]) in Western South Pacific island locations. The GPS data are scattered data only helpful to detect the presence or absence of a general subsidy for the area of the tide gauge. No conclusive statement can be made about the vertical stability of the tide gauge from these data. The reading of the tide gauge may also be biased upwards or downwards by other factors additional to subsidence or uplift. 
23] also has a rate of rise of $1.04 \mathrm{~mm} /$ year over a composite record spanning 85 years.

The computed SLR represent the relative motion sea vs. land that ultimately is the parameter to consider to assess the risk of inundation. The vertical motion of the land, positive (uplift) or negative (subsidence), the positive or negative vertical motion of the tide gauge and the many other factor affecting the measurement accuracy may be responsible of outliers like Rabal, PNG and Noumea, New Caledonia recording negative SLR or Suva, Fiji, recording a SLR much higher than in the neigboring islands. Not surprisingly, the most part of the Pacific islands is affected by subsidence.

\section{Discussion}

The early 1990s were a clear deep of the deep and valley SOI oscillations, the multi-decadal periodicity very well known to affect the Australian sea levels. Both the Australian Baseline and the Pacific sea level monitoring projects all start in these days.

The SOI influence is very well known for the area. The Australian sea level surveys were conducted in the past by using at least 30 years of data with graphs of local mean sea levels accompanied by the graph of the SOI oscillation (see the 2003 survey [19] as well as the censored 2009 survey [20]).

Measurements started early 1990s about a valley of a SOI peak and valley oscillation are expected to bias upwards the rates of rise of sea levels computed in these stations up to the mid-2050s.

In addition to the multi-decadal oscillation of period about 20 years, there is a quasi-60 year multi-decadal periodicity.

Sydney, NSW and Auckland, NZ are unfortunately the only two centenary tide gauges of the Western South Pacific, with the Auckland tide gauge unfortunately discontinued in the year 2000. Further analyses of the Sydney tide gauge as well as of other Pacific tide gauges may be found in $[7,11]$.

Many tide gauges of the Pacific are located in atoll islands. Charles Darwin [24] explained the creation of coral atolls in the Pacific Ocean as a sequence of gradual subsidence of what started as an oceanic volcano through barrier reef island to atoll. Therefore, it is not a novelty that atolls are subject to subsidy.

Subsidy is the main reason why some atolls of the $\mathrm{Pa}$ cific have rates of rise of sea levels as measured by tide gauges higher than other islands or along the continental coast of Australia. Heavy constructions on subsiding atolls may increase the apparent rate of rise of sea levels measured by the tide gauges.

The SLR values of Tables 1 and 2 nominally account for the vertical motion of the tide gauge as well as for the barometric pressure. However, while the theory of [13-16] is certainly solid, the large number of accuracy issues affecting the final result makes the practice unreliable.

\section{Conclusions}

For the Australian Pacific coast and the Western South Pacific, there is an important multi-decadal oscillation of the oceans with a periodicity close to the 20 years. In addition to this periodicity, it has been shown here the existence of a longer periodicity of quasi 60 years. As a consequence of the multi-decadal oscillations, the analysis of short records of less than 20 years produces unrealistic rates of rise of sea levels.

Some more realistic values of the rate of rise of sea levels have been proposed for the stations of Tables 1 and 2 . The more realistic rates of rise of sea levels are roughly $30 \%$ of the values proposed without accounting for the subsidy common to many atoll locations. The actual rate of rise of the sea level is expected to be further reduced.

An integrated global observing system linking both the tide gauge and the GNSS databases is certainly needed for a better description of the sea level behaviour. However, the development of the technique up to a level of accuracy permitting the measure of the sea level accelerations postulated in the climate models does not seem a matter of few years. Without at least 60 years of continuing recording of good data estimations of the rate of rise may be misleading.

\section{References}

[1] J. Church, N. White, (2006), A 20 th century acceleration in global sea-level rise, Geophysical Research Letters 33: L01602.

[2] R. J. Nicholls, A. Cazenave, (2010), Sea-Level Rise and Its Impact on Coastal Zones, Science Magazine 328 (5985): 15171520.

[3] IPCC (2007), AR4 WG1.

[4] A. Parker, (2013), Comment to M Lichter and D Felsenstein, Assessing the costs of sea-level rise and extreme flooding at the local level: A GIS-based approach, Ocean \& Coastal Management 59 (2012) 47-62, Ocean and Coastal Management, 78 , pp. 38-142. 
[5] A. Parker, (2013), Comment on "Low-frequency sea level variation and its correlation with climate events in the Pacific", Chinese Science Bulletin, 58 (14), pp. 1708-1713.

[6] T. Watson, A. Parker, (2013), Comment to Hunter et al., Towards a global regionally varying allowance for sea-level rise, Ocean Engineering, in press, corrected proof, Ocean Engineering, Article in Press.

[7] A. Parker, M. Saad Saleem, M. Lawson, (2013), Sea-level trend analysis for coastal management, Ocean and Coastal Management, 73, pp. 63-81.

[8] A. Parker, (2013), Sea level trends at locations of the United States with more than 100 years of recording, Natural Hazards, 65 (1), pp. 1011-1021.

[9] A. Parker, (2013), Comment to Shepard, C.C., Agostini, V.N., Gilmer, B., Allen, T., Stone, J., Brooks, W., Beck, M.W.: Assessing future risk: Quantifying the effects of sea level rise on storm surge risk for the southern shores of Long Island: New York, Natural Hazards, Volume 60, Issue 2, January 2012, pp 727-745, Natural Hazards, 65 (1), pp. 977-980.

[10] A. Parker, (2013), Oscillations of sea level rise along the Atlantic coast of North America north of Cape Hatteras, Natural Hazards, 65 (1), pp. 991-997.

[11] A. Parker, (2013), Natural oscillations and trends in longterm tide gauge records from the Pacific, Pattern Recogn. Phys., 1, 1-13, 2013. www.pattern-recogn-phys.net/1/1/2013/. DOI:10.5194/prp-1-1-2013.

[12] Permanent service on Mean Sea Level PSMSL (2012), Sea level data. www.psmsl.org

[13] Australian Government Bureau of Meteorology AGBOM (2012), The South Pacific Sea Level \& Climate Monitoring Project. www.bom.gov.au/pacificsealevel/index.shtml

[14] Australian Government Bureau of Meteorology AGBOM (2012), The South Pacific sea level \& climate monitoring project monthly data Report No. 204, June 2012. www.bom.gov.au/ ntc/ID060101/ID060101.201206.pdf

[15] Australian Government Bureau of Meteorology AGBOM (2012), The Australian Baseline Sea Level Monitoring Project. www. bom.gov.au/oceanography/projects/abslmp/abslmp.shtml

[16] Australian Government Bureau of Meteorology AGBOM (2012), The Australian Baseline Sea Level Monitoring Project Monthly Data Report june 2012. www.bom.gov.au/ntc/ID060201/ ID060201.201206.pdf

[17] CU Sea Level Research Group (2013), Global Mean Sea Level. sealevel.colorado.edu

[18] National Oceanic \& Atmospheric Administration Research Physical Sciences Division NOAA (2012), Climate Indices: Monthly Atmospheric and Ocean Time Series. www.esrl.noaa. gov/psd/data/climateindices/list/

[19] Australian Government Bureau of Meteorology AGBOM (2006), Australian Mean Sea Level Survey 2003. www.environment. gov.au/soe/2006/publications/drs/pubs/366/co/co_03_ aust_mean_sea_level_survey_2003.pdf

[20] Australian Government Bureau of Meteorology AGBOM (2009), Australian Mean Sea Level Survey 2009. www.conscious.com. au/docs/new/128.21_AustMSLsurvey2009(2).pdf

[21] Australian Government Bureau of Meteorology AGBOM (2013), S.O.I. (Southern Oscillation Index) Archives - 1876 to present. www.bom.gov.au/climate/current/soihtm1.shtml

[22] D. P. Chambers, M. A. Merrifield, R. S. Nerem (2012), Is there a 60 -year oscillation in global mean sea level?, Geophysical
Research Letters, Volume 39, Issue 18, L052885.

[23] NOAA (2013), sea level trends. www.tidesandcurrents.noaa. gov/sltrends/

[24] C. R. Darwin, (1842), The structure and distribution of coral reefs. Being the first part of the geology of the voyage of the Beagle, under the command of Capt. Fitzroy, R.N. during the years 1832 to 1836, London, Smith Elder and Co.

[25] SONEL (2013), GPS stations. www.sonel.org/-GPS-.html

Received June 6, 2013; accepted October 22, 2013. 